\title{
Efeito da Lei do Programa Nacional de Alimentação Escolar na qualidade nutricional dos cardápios escolares
}

\author{
Daniela Bicalho Alvarez ${ }^{1}$ e Betzabeth Slater Villar ${ }^{2}$
}

O Programa Nacional de Alimentação Escolar (PNAE) é uma política pública de estratégia de alcance da Segurança Alimentar e Nutricional. O objetivo do estudo é avaliar o efeito da implementação da lei do PNAE na qualidade nutricional dos cardápios escolares do estado de São Paulo. Trata-se de estudo transversal, com base na tríade de avaliação Estrutura - Processo - Resultado e elaboração de matriz avaliativa, conduzido em 2013. Trinta e oito municípios do estado de São Paulo foram divididos em dois grupos: os que adquirem gêneros da agricultura familiar e os que não adquirem. A coleta de dados foi realizada por meio dos cardápios escolares e um questionário estruturado com nutricionistas. Os alimentos dos cardápios foram categorizados segundo a extensão e propósito de processamento e a qualidade nutricional foi avaliada conforme os parâmetros da legislação vigente. Foram utilizadas estatística descritiva e teste exato de Fischer para análise de associação. Vinte e cinco municipios adquiriam alimentos da agricultura familiare 18 não implementaram as compras. Os municípios que compraram alimentos dos agricultores familiares tiveram prevalência de $76 \%$ de cozinheiros escolares em número suficiente e $60 \%$ realizaram ações de apoio com os agricultores familiares $(p>0,05)$. Quase a totalidade das cidades, de ambos os grupos, atenderam a legislação quanto a oferta mínima de frutas ou hortaliças (96\%) e máxima de doces (84\%). A participação média de alimentos ultraprocessados nos lanches foi de 8 itens para municípios que fazem as compras dos agricultores e 13 itens para os que não o fazem. Concluímos que ambos os grupos atendem a obrigatoriedade da lei quanto a oferta de frutas ou hortaliças e de doces, porém a participação média de alimentos ultraprocessados é elevada.

Palavras-chave: Alimentação Escolar, planejamento de cardápios, avaliação de programas, programas e políticas em nutrição, indicadores.

\section{Effect of the National School Feeding Program's Law on the nutritional quality of school menus}

The National School Feeding Program (PNAE) is a public policy strategy for achieving Food and Nutrition Security. We evaluated the effect of the Brazilian Federal Law 11,947/09 in the nutritional quality of the school menus by São Paulo's State. This is a cross-sectional study conducted in 2013 and based on structure - process results framework with drafting evaluative matrix. Thirty-eight cities of São Paulo's State were divided into 2 groups: cities who purchases family farming food and cities who did not purchases. Data were collected through

1 Doutoranda e Mestre em Ciências pela Faculdade de Saúde Pública da Universidade de São Paulo. Endereço para correspondência: Av. Doutor Arnaldo no 715 - Cerqueira César, São Paulo, SP. Telefone: +55 (11) 3061-7853. E-mail: bicalhodaniela@gmail.com

2 Professor Livre Docente, Doutor (PhD) e Mestre em Ciências pela Faculdade de Saúde Públic, Universidade de São Paulo. Endereço para correspondência: Av. Doutor Arnaldo no 715 - Cerqueira César, São Paulo, SP. Telefone: +55 (11) 3061-7853. E-mail: bslater@usp.com.br 
school menus and interviews with nutritionist by a previous structured questionnaire. Foods of the menus were analyzed according extension and processing purpose. Descriptive statistics and Exact Fisher test analysis were calculated. 25 municipalitiespurchase some family farming food and 18 did not implement it. Municipalities that purchase from family farming food had a higher prevalence of enough school cooks $(76 \%)$ and carry out actions to support family farmers $(60 \%)$ in the region ( $p>0.05)$. Most cities of both groups comply the legislation regarding the minimum supply of fruits or vegetables $(96 \%)$ and maximum of sweets $(84 \%)$. The average of ultraprocessed foods in snacks was 8 items for municipalities that buy family farmers and 13 items for those who do not. We conclude that both groups obey the law regarding the supply of fruits or vegetables and sweets, but the participation of ultraprocessed foods is high.

Keywords: school nutrition, menu planning, nutrition programs and policies, program evaluation, indicator.

\section{INTRODUÇÃO E OBJETIVOS}

O Programa Nacional de Alimentação Escolar (PNAE) é a política pública mais antiga de proteção social vigente no Brasil, sendo considerado um dos maiores, mais abrangentes e duradouros programas na área de alimentação escolar do mundo, no que se refere ao atendimento universal dos estudantes e garantia do Direito Humano à Alimentação Saudável e Adequada[1-3]. Este Programa tem por objetivo contribuir no crescimento e o desenvolvimento biopsicossocial, na aprendizagem, no rendimento escolar, bem como na formação de práticas alimentares saudáveis, por meio de ações de educação alimentar e nutricional e da oferta de refeições que cubram as necessidades nutricionais dos estudantes durante o período em que permanecem na escola $^{[4-5]}$.

Em 2009, ocorreu a promulgação da Lei no 11.947 que no seu artigo 14 consolida a vinculação do PNAE com à agricultura familiar, estabelecendo a obrigatoriedade da aquisição de gêneros alimentícios diretamente dos agricultores familiares, empreendedores familiares rurais ou de suas organizações. Para tanto, os municípios e estados devem utilizar no mínimo 30\% do total de recursos financeiros destinados à execução do programa, provenientes do Fundo Nacional de Desenvolvimento da Educação[4].

Esta vinculação se destaca como uma iniciativa inovadora, que vai ao encontro das estratégias de Segurança Alimentar e Nutricional (SAN), buscandootimizar e articular programas, políticas e recursos públicos para combater a insegurança alimentar e nutricional e promover o desenvolvimento local de maneira sustentável[[].
Isso reforça o dispositivo legal que inștitui a Política Nacional de Segurança Alimentar e Nutricional (PNSAN), que se fundamenta no direito humano ao acesso regular e permanente a alimentos em quantidade e variedade necessárias para manter a pessoa saudável[7].

O PNAE está inserido na PNSAN como um dos seus eixos estruturantes de acesso aos alimentos [7]. Dessa forma, o cardápio escolar é um instrumento de acesso a alimentos aos estudantes que possibilita a diversificação dos hábitos alimentares dos estudantes e o fortalecimento da cultura alimentar local[8]. O planejamento de cardápio deve assegurar a oferta de uma alimentação saudável e adequada, que garanta o atendimento das necessidades nutricionais dos alunos durante o período letivo e atue como um elemento pedagógico, caracterizando uma importante ação de educação alimentar e nutricional. estar alinhado com os objetivos e diretrizes do PNAE[5].

Tendo em vista as modificações advindas da legislação e objetivo do PNAE é necessário identificar os alimentos que compõem os cardápios das escolas e as práticas de aquisição de alimentos da agricultura familiar. Assim como o impacto da intervenção do artigo 14 da legislação vigente na qualidade nutricional da alimentação escolar, por meio de estudos avaliativos que verifiquem se esta ferramenta política traz ganhos na qualidade da alimentação e na saúde dos milhões de estudantes brasileiros da educação pública ${ }^{[9-10]}$. Até o presente momento, não foram encontrados na literatura estudos que avaliem o efeito desta Lei na qualidade nutricional dos cardápios do Programa. Este estudo tem como objetivo avaliar o efeito da 
implementação do artigo 14 da Lei Federal 11.947/09 na qualidade dos cardápios propostos pelo Programa Nacional de Alimentação Escolar em municípios do estado de São Paulo. avaliação de qualidade de serviços Estrutura Processo - Resultado proposta por Donabedian[11] e adaptada para as políticas de segurança alimentar e nutricional[12].

\section{MATERIAL E MÉTODOS}

Trata-se de um estudo transversal. Para essa avaliação se desenvolveu uma Matriz Avaliativa (Tabela 1), com base na tríade de

Tabela 1. Matriz avaliativa do efeito da Lei 11.947/09 na qualidade nutricional dos cardápios. São Paulo, 2013

\begin{tabular}{ccccc}
\hline & Dimensão Estrutura & Parâmetro & Juízo de Valor \\
\hline Subdimensão & Indicador & Medida & Sim \\
Infraestrutura & $\begin{array}{c}\text { 1. Condições adequadas } \\
\text { de recebimento, } \\
\text { armazenamento, } \\
\text { conservação e preparo } \\
\text { dos alimentos }\end{array}$ & $\begin{array}{c}\text { Cidade com escolas em condições } \\
\text { adequadas de recebimento, } \\
\text { armazenamento, conservação e } \\
\text { preparo dos alimentos }\end{array}$ & Não & Adequado \\
Recursos Humanos & $\begin{array}{c}\text { Inadequado } \\
\text { em número suficiente }\end{array}$ & $\begin{array}{c}\text { Município com cozinheiros } \\
\text { escolares suficiente nas escolas }\end{array}$ & Adequado \\
\hline
\end{tabular}

Dimensão Processo

\begin{tabular}{|c|c|c|c|c|c|}
\hline Subdimensão & Indicador & \multicolumn{2}{|l|}{ Medida } & Parâmetro & Juízo de Valor \\
\hline \multirow{4}{*}{$\begin{array}{l}\text { Mecanismos para } \\
\text { implementação da } \\
\text { aquisição de gêneros } \\
\text { da agricultura } \\
\text { familiar }\end{array}$} & \multirow{4}{*}{$\begin{array}{l}\text { 3. Ações de apoio aos } \\
\text { agricultores } \\
\text { 4. Mapeamento dos } \\
\text { alimentos produzidos } \\
\text { pelos agricultores }\end{array}$} & \multirow{2}{*}{\multicolumn{2}{|c|}{$\begin{array}{l}\text { Gestor que realiza ações de apoio } \\
\text { aos agricultores }\end{array}$}} & $\operatorname{Sim}$ & Adequado \\
\hline & & & & Não & Inadequado \\
\hline & & \multirow{2}{*}{\multicolumn{2}{|c|}{$\begin{array}{l}\text { Nutricionista que realiza } \\
\text { mapeamento de alimentos da } \\
\text { agricultura familiar }\end{array}$}} & $\operatorname{Sim}$ & Adequado \\
\hline & & & & Não & Inadequado \\
\hline \multicolumn{6}{|c|}{ Dimensão Resultado } \\
\hline Subdimensão & Indicador & Medida & & metro & Juízo de Valor \\
\hline \multirow{8}{*}{$\begin{array}{l}\text { Qualidade } \\
\text { nutricional dos } \\
\text { cardápios }\end{array}$} & \multirow{2}{*}{$\begin{array}{l}\text { 5. Porções de frutas ou } \\
\text { hortaliças }\end{array}$} & \multirow{2}{*}{\multicolumn{2}{|c|}{$\begin{array}{l}\text { Número de porções de } \\
\text { frutas ou hortaliças }\end{array}$}} & orções & Adequado \\
\hline & & & & orções & Inadequado \\
\hline & \multirow[b]{2}{*}{ 6. Porções de doces } & \multirow{2}{*}{$\begin{array}{l}\text { Número de porções de } \\
\text { doces }\end{array}$} & & orções & Adequado \\
\hline & & & & orções & Inadequado \\
\hline & \multirow[b]{2}{*}{$\begin{array}{l}\text { 7. Participação de } \\
\text { alimentos básicos }\end{array}$} & \multirow{2}{*}{$\begin{array}{l}\% \text { de alimentos in } \\
\text { natura, minimamente } \\
\text { processados e } \\
\text { ingredientes culinários }\end{array}$} & $\geq 70 \%$ & nentos básicos & Adequado \\
\hline & & & $<70 \%$ & nentos básicos & Inadequado \\
\hline & \multirow{2}{*}{$\begin{array}{l}\text { 8. Participação de } \\
\text { alimentos restritos }\end{array}$} & \multirow{2}{*}{$\begin{array}{l}\% \text { de alimentos } \\
\text { processados e } \\
\text { ultraprocessados }\end{array}$} & $\leq 30 \% \mathrm{c}$ & hentos restritos & Adequado \\
\hline & & & $>30 \%$ & hentos restritos & Inadequado \\
\hline
\end{tabular}

Fonte: Autores. 
A dimensão Estrutura é uma abordagem que considera as características relativamente estáveis do PNAE, tais como instrumentos, recursos, estruturas físicas e organizacionais. Neste caso, foram investigados itens relacionados às condições para a disponibilidade do fornecimento dos alimentos da agricultura familiar para os alunos, sendo: condições adequadas de infraestrutura da escola e número suficiente de manipuladores de alimentos.

A dimensão Processo corresponde a todas as atividades e procedimentos realizados pelos profissionais envolvidos no cuidado dos beneficiários. Para isso, foram investigados os mecanismos para implantação da aquisição de gêneros da agricultura familiar, por meio da verificação de ações de apoio do gestor para implementação das compras e realização de mapeamento dos alimentos produzidos pelos agricultores familiares da região pelo nutricionista do município.

A dimensão Resultado é representada por características do contexto que foram modificadas na interação com o Processo, que possam ser imputadas à intervenção realizada. Nesta dimensão foram investigados a qualidade nutricional dos cardápios planejados pelos nutricionistas do programa, por meio da análise da frequência semanal dos alimentos presentes nos cardápios das escolas conforme a extensão de processamento e o limite máximo de $30 \%$ de alimentos restritos e 2 porções para oferta de doces e mínimo de $70 \%$ de alimentos básicos e 3 porções para frutas e hortaliças, conforme exigência da legislação vigente.

Para a construção da matriz avaliativa o grupo de pesquisa se apoiou na revisão da literatura, nos princípios e diretrizes do PNAE estabelecidos pela Lei no11.947/2009[5], pela Resolução no26/2015[4] do Fundo Nacional de Desenvolvimento da Educação e pelo Guia Alimentar da População Brasileira ${ }^{[13]}$. O grupo de trabalho foi composto por estudantes de mestrado e doutorado e professor pesquisador do Departamento de Nutrição da Faculdade de Saúde Pública da Universidade de São Paulo com experiencia na prática e em pesquisa. Foram desenvolvidos 8 indicadores e definidos parâmetros para cada um deles. Os juízos de valor foram designados como "adequado" ou "inadequado" segundo os parâmetros definidos para cada indicador.

Para a avaliação foi selecionada uma amostra representativa de municípios do estado de São Paulo ${ }^{1}$, divididos em dois grupos: grupo 1 composto por municípios que realizam compra de alimentos da agricultura familiar e grupo 2 municípios que não fazem a compra. Com o intuito de contemplar no processo amostral das características regionais, socioculturais e agroeconômicas dos municípios, as 63 microrregiões do estado de São Paulo foram reagrupadas por conveniência em seis regiões considerando os seus limites com outros estados e o Oceano Atlântico.

Os municípios foram distribuídos aleatoriamente e proporcionalmente dentro das regiões definidas previamente, em seguida, a estratégia amostral adotada foi selecionar aleatoriamente municípios nestes estratos. Os municípios selecionados foram: Avaí, Barra Bonita, Barueri, Capivari, Cunha, Floreal, Francisco Morato, Guarujá, Ilhabela, Itatinga, Júlio Mesquita, Lavínia, Limeira, Lucélia, Maracaí, Meridiano, Mococa, Mogi Guaçu, Monte Azul Paulista, Monteiro Lobato, Onda Verde, Orindiúva, Ouro Verde, Peruíbe, Populina, Reginópolis, Registro, Ribeirão Bonito, Sabino, Sagres, São Sebastião da Grama, Sete Barras, Tabapuã, Torrinha, Turiuba, Uchoa, Valinhos e Vargem.

A coleta dos dados primários foi realizada em 2013, por nutricionistas e estudantes de nutrição previamente treinados, por meio de entrevista individual com questionário estruturado, aplicado com os nutricionistas responsáveis técnicos do PNAE. Também foi coletado o cardápio de um mês do ano de 2012 das escolas de educação infantil e fundamental da rede municipal pública, que atendem alunos na faixa etária de 4 a 6 anos e 6 a 14 anos, respectivamente.

$\mathrm{Na}$ avaliação foi considerado os dados do cardápio da primeira semana típica do mês, ou seja, com 5 dias úteis de segunda a sexta feira, não precedida ou seguida de feriados, nem situada em meses tradicionais de férias. Deste modo, é possível obter dados que possibilitem conhecer a situação e 
que permitam a construção de uma linha de base para o processo de avaliação[14].

Para avaliação dos cardápios foram considerados as refeições tipo lanche e o almoço. Os itens propostos nos cardápios foram analisados segundo os critérios da NOVA - classificação que categoriza os alimentos de acordo com a extensão e o propósito de seu processamento[15]. Segundo essa classificação, os itens alimentares são alocados em um dos quatro grupos: alimentos in natura ou minimamente processados; ingredientes culinários processados; alimentos processados; e alimentos ultraprocessados.

As preparações culinárias informadas nos cardápios foram desmembradas em alimentos para a análise do componente principal da receita em um dos grupos da NOVA. Para saber quais os ingredientes de cada preparação, foi consultada a literatura de receituário-padrão[16] e as receitas fornecidas por algumas escolas. Já para aquelas escolas cuja as preparações não haviam a receita, foi considerado o ingrediente principal para a análise.

A qualidade nutricional dos cardápios foi avaliada conforme os parâmetros da legislação do PNAE, que estabelece o mínimo de aquisição de $70 \%$ de alimentos básicos e o máximo de 30\% de alimentosrestritos, bem como o limite de 2 porções de doces e o mínimo de 3 porções de frutas e hortaliças ${ }^{[5]}$.

Neste estudo, se entendeu que os alimentos básicos sejam in natura, minimamente processados ou ingredientes culinários e os alimentos restritos são os processados e ultraprocessados. Foi necessário adotar esse entendimento, visto que a normatização não discrimina quais são os alimentos básicos e estabelece como restrito a aquisição de alimentos alguns alimentos processados e ultraprocessados: enlatados, embutidos, doces, alimentos compostos (dois ou mais alimentos embalados separadamente para consumo) preparações semi prontas (ou prontas) para consumo ou alimentos concentrados (pó ou desidratados para reconstituição) $)^{[4]}$.

As informações secundárias necessárias para caracterização socioeconômica dos municípios estudados foram levantadas em base de dados de livre acesso: Atlas de Desenvolvimento para o Índice de Desenvolvimento Municipal (IDHM) e Instituto Brasileiro de Geografia e Estatística (IBGE) para Estatísticas econômicas dos municípios (Censo 2010) ${ }^{[17-18] .}$

As análises estatísticas foram realizadas utilizando o Software Data Analysis and Statistical (Stata) versão 13.0. $\mathrm{Na}$ análise descritiva foram calculadas frequências absolutas e médias. Para às análises de associação se utilizou o teste exato de Fischer, com um nível de significância estatística de $5 \%(\mathrm{p}<0,05)$.

O estudo teve aprovação do Comitê de ética em Pesquisa, número 47187015.0.0000.5421. Todas as informações foram coletadas para aqueles indivíduos que assinaram o Termo de Consentimento Livre e Esclarecido, para atender a Resolução 466 de Dezembro de 2012.

\section{RESULTADOS}

A amostra é semelhante quanto as características socioeconômicas, sendo a maioria de pequeno porte populacional $(n=29)$ e IDHM alto ou muito alto $(\mathrm{n}=35)$. Dos 38 municípios da amostra, vinte e cinco adquirem algum gênero alimentício da agricultura familiar e 18 cidades não implementaram suas compras. Com relação a exigência em lei da utilização mínima de 30\% dos recursos financeiros repassados pelo governo federal para a compra de alimentos da agricultura familiar, quase metade das cidades que adquirem esses gêneros não cumprem o percentual determinado.

Os resultados da distribuição de municípios com juízo de valor "adequado", segundo os indicadores da matriz avaliativa e da análise de associação municípios que adquirem e não adquirem gêneros da agricultura familiar estão apresentados na Tabela 2 e 3, respectivamente.

$\mathrm{Na}$ dimensão Estrutura, a maior parte dos municípios de ambos os grupos estão inadequados para o indicador "condições adequadas de recebimento, armazenamento, conservação e preparo de alimentos". A infraestrutura das escolas está adequada em apenas $36 \%$ das cidades que adquirirem gêneros da agricultura familiar. Os 
recursos humanos para manipulação dos alimentos estão em número suficiente em $76 \%$ dos municípios que compram alimentos da agricultura familiar $(\mathrm{p}<0,05)$.

No entanto, na dimensão Processo, o porcentual de municípios com juízo de valor "adequado" é elevado para o indicador "mapeamento dos alimentos produzidos pelos agricultores". Os gestores de 60\% das cidades que compram alimentos da agricultura familiar realizam ações de apoio aos agricultores $(p<0,05)$. Os nutricionistas que realizam mapeamento dos alimentos produzidos pelos agricultores familiares são $80 \%$ e $61 \%$ dos municípios que compram e não compram gêneros da agricultura familiar, respectivamente.

$\mathrm{Na}$ dimensão Resultado, quase a totalidade das cidades dos dois grupos atendem a legislação federal vigente no que se refere a obrigatoriedade do cardápio ofertar o mínimo de 3 porções de frutas ou hortaliças e o máximo de 2 porções doces para os estudantes. No entanto, o grupo de municípios que adquirem gêneros alimentícios da agricultura familiar tem maior porcentual $(83 \%)$ para o indicador de qualidade nutricional de cardápio "participação de alimentos básicos" e menor frequência para o indicador "participação de alimentos restritos".

Tabela 2. Distribuição de municípios com juízo de valor "adequado", segundo as dimensões, subdimensões e indicadores. São Paulo, 2013

\begin{tabular}{|c|c|c|c|c|c|}
\hline \multirow[b]{2}{*}{ Dimensão } & \multirow[b]{2}{*}{ Subdimensão } & \multirow[b]{2}{*}{ Indicador } & \multicolumn{2}{|c|}{ Aquisição da Agricultura Familiar } & \multirow{2}{*}{$\begin{array}{l}\text { Total } \\
\%(n)\end{array}$} \\
\hline & & & $\underset{\%}{\operatorname{Sim}(\mathrm{n})}$ & $\begin{array}{l}\text { Não } \\
\%(n)\end{array}$ & \\
\hline \multirow[t]{2}{*}{ Estrutura } & \multirow[t]{2}{*}{$\begin{array}{l}\text { Infraestrutura e recursos } \\
\text { humanos nas escolas }\end{array}$} & $\begin{array}{c}\text { Condições } \\
\text { adequadas de } \\
\text { recebimento, } \\
\text { armazenamento, } \\
\text { conservação e } \\
\text { preparo de } \\
\text { alimentos }\end{array}$ & $23,7(9)$ & $15,8(6)$ & $39,5(15)$ \\
\hline & & $\begin{array}{l}\text { Cozinheiros } \\
\text { escolares em } \\
\text { número suficiente }\end{array}$ & $50,0(19)$ & $13,2(5)$ & $63,2(24)$ \\
\hline \multirow[b]{2}{*}{ Processo } & \multirow[b]{2}{*}{$\begin{array}{l}\text { Mecanismos para } \\
\text { implementação da } \\
\text { aquisição de gêneros da } \\
\text { Agricultura Familiara }\end{array}$} & $\begin{array}{l}\text { Ações de apoio aos } \\
\text { agricultores }\end{array}$ & $39,5(15)$ & $2,7(1)$ & $42,1(16)$ \\
\hline & & $\begin{array}{l}\text { Mapeamento dos } \\
\quad \text { alimentos } \\
\text { produzidos pelos } \\
\text { agricultores }\end{array}$ & $52,6(20)$ & $21,1(8)$ & $73,7(28)$ \\
\hline \multirow{4}{*}{ Resultado } & \multirow{4}{*}{$\begin{array}{l}\text { Qualidade nutricional dos } \\
\text { cardápios }^{\text {b }}\end{array}$} & $\begin{array}{c}\text { Porções de frutas ou } \\
\text { hortaliças }\end{array}$ & $68,0(17)$ & $28,0(7)$ & $96,0(24)$ \\
\hline & & Porções de doces & $64,0(16)$ & $20,0(5)$ & $84,0(21)$ \\
\hline & & $\begin{array}{l}\text { Participação de } \\
\text { alimentos básicos }\end{array}$ & $56,0(14)$ & $12,0(3)$ & $68,0(17)$ \\
\hline & & $\begin{array}{l}\text { Participação de } \\
\text { alimentos restritos }\end{array}$ & $60,0(15)$ & $12,0(3)$ & $72,0(18)$ \\
\hline
\end{tabular}

Fonte:

a Número de observações $\mathrm{n}=38$

b Número de observações $n=25$ 
Para além da qualidade nutricional analisada segundo os critérios da Lei 11.947/09, também foi analisado que a participação média semanal dos alimentos ultraprocessados nos cardápios é elevada. Verificou-se no lanche uma média de 13 itens para municípios que não adquirem gêneros da agricultura familiar e de 8 itens para municípios que compram alimentos dos agricultores familiares. Entretanto, na refeição a média de alimentos ultraprocessados é inferior, sendo de 1 item para as cidades que não compram alimentos da agricultura familiar e 2 itens para os municípios que compram da agricultura familiar.
A frequência dos alimentos in natura e minimamente processados é elevada em ambos os grupos de municípios: 1 ou 2 vezes por semana para frutas; 3 ou 4 vezes por semana para o grupo dos feijões e das carnes e ovos; e 5 ou mais vezes por semana para o grupo das hortaliças e cereais ou macarrão. Para os alimentos processados se destaca a presença do molho de tomate 1 a duas vezes na semana. Os alimentos ultraprocessados com maior frequência semanal nos cardápios de ambos os municípios são: pão, biscoito, embutidos, suco tipo néctar, gelatina (Apêndice 1).

Tabela 3. Análise de associação municípios do estado de São Paulo que adquirem e não adquirem gêneros da agricultura familiar, de acordo características socioeconômicas, e indicadores da matriz avaliativa. São Paulo, Brasil, 2013

\begin{tabular}{|c|c|c|c|c|}
\hline \multirow[b]{2}{*}{ Variáveis } & \multicolumn{4}{|c|}{ Aquisição da Agricultura Familiar } \\
\hline & Categorias & $\operatorname{Sim}_{\%(\mathrm{n})}$ & $\begin{array}{l}\text { Não } \\
\% \text { (n) }\end{array}$ & $p^{*}$ \\
\hline \multicolumn{5}{|c|}{ Características Socioeconômicas $^{a}$} \\
\hline \multirow[t]{3}{*}{ Porte populacional } & Pequeno & $80,0(20)$ & $69,2(9)$ & \\
\hline & Médio & $8,0(2)$ & $7,7(1)$ & 0,72 \\
\hline & Grande & $12,0(3)$ & $23,1(3)$ & \\
\hline \multirow{2}{*}{$\begin{array}{l}\text { Índice de } \\
\text { Desenvolvimento Humano } \\
\text { Municipal }\end{array}$} & Médio & $12,0(3)$ & $7,7(1)$ & 0,58 \\
\hline & Alto e Muito Alto & $88,0(22)$ & $92,3(13)$ & \\
\hline \multicolumn{5}{|c|}{ Infraestrutura e recursos humanos nas escolas a } \\
\hline $\begin{array}{l}\text { Condições adequadas de } \\
\text { recebimento, armazena- }\end{array}$ & $\operatorname{Sim}$ & $36,0(9)$ & $46,2(6)$ & 0,58 \\
\hline $\begin{array}{l}\text { mento, conservação e } \\
\text { preparo de alimentos }\end{array}$ & Não & $64,0(16)$ & $53,9(7)$ & \\
\hline Cozinheiros escolares em & Sim & $76,0(19)$ & $38,5(5)$ & $0,03^{* *}$ \\
\hline número suficiente & Não & $24,0(6)$ & $61,5(8)$ & \\
\hline \multicolumn{5}{|c|}{ Mecanismos para implementação da aquisição de gêneros da Agricultura Familiara } \\
\hline \multirow{4}{*}{$\begin{array}{l}\text { Ações de apoio aos agricul- } \\
\text { tores } \\
\text { Mapeamento dos alimentos } \\
\text { produzidos pelos agriculto- } \\
\text { res }\end{array}$} & Sim & $60,0(15)$ & 9,1 (1) & $0,01 * *$ \\
\hline & Não & $40,0(10)$ & $90,9(10)$ & \\
\hline & Sim & $80,0(20)$ & $61,5(8)$ & 0,20 \\
\hline & Não & $20,0(5)$ & $38,5(5)$ & \\
\hline \multicolumn{5}{|c|}{ Qualidade nutricional dos cardápios ${ }^{\mathrm{b}}$} \\
\hline Mínimo de 3 porções de & Sim & $94,4(17)$ & $100,0(7)$ & 0,72 \\
\hline frutas ou hortaliças & Não & $5,6(1)$ & $0,0(0)$ & \\
\hline Máximo de 2 porções de & Sim & $88,9(16)$ & $71,4(5)$ & 0,31 \\
\hline doces & Não & $11,1(2)$ & $28,6(2)$ & \\
\hline Participação $\geq 70 \%$ de & Sim & $77,78(14)$ & $42,9(3)$ & 0,12 \\
\hline alimentos básicos & Não & $22,2(4)$ & $57,2(4)$ & \\
\hline Participação $\leq 30 \%$ de & $\operatorname{Sim}$ & $83,3(15)$ & $42,9(3)$ & 0,07 \\
\hline alimentos restritos & Não & $16,7(3)$ & $57,2(4)$ & \\
\hline
\end{tabular}

\section{DISCUSSÃO}

O marco legal apresenta lacunas quanto a definição dos alimentos que devem compor os cardápios das escolas da rede pública de ensino, sendo permissivo quanto ao uso de alimentos de maior nível de processamento. Estas lacunas podem ser preenchidas com uma concepção mais clara em legislação sobre os alimentos básicos e mais rígida sobre os alimentos restritos, visando melhor qualidade nutricional da alimentação fornecida aos milhões de estudantes atendidos. Cabe destacar que a legislação atual do PNAE é 
anterior a publicação do instrumento oficial que classifica os alimentos conforme a extensão e propósito de processamento, fato que reforça a necessidade de atualização da normativa.

A efetivação das compras diretas de gêneros alimentícios da agricultura familiar para alimentação escolar dos municípios ainda está em processo de implementação no período estudado. Os resultados de um estudo nacional mostram que cerca da metade dos municípios brasileiros adquirem alimentos da agricultura familiar para a alimentação escolar e a média do percentual de compras não atingiu o mínimo percentual exigido em lei[19]. Outro estudo com 613 municípios do estado de São Paulo verificou que quase metade destes municípios já implementaram as compras locais para o PNAE em todas as suas etapas, pelo menos uma vez, ou seja, publicaram pelo menos uma chamada pública, receberam os produtos e realizaram o pagamento aos produtores ${ }^{[20]}$. Uma pesquisa em Santa Catarina que avaliou o cumprimento das recomendações do PNAE para a aquisição de alimentos da agricultura familiar identificou que ainda devem ser exploradas fragilidades do programa para efetivação da normativa nos diferentes contextos das regiões brasileiras, contribuindo de fato para fomentar a agricultura local e melhorar a qualidade da alimentação escolar no município[21].

$\mathrm{Na}$ dimensão estrutura, a quantidade adequada de recursos humanos (merendeiros) está relacionada com municípios que adquirem alimentos da agricultura familiar, entretanto a infraestrutura - condições adequadas de recebimento, armazenamento, conservação e preparo dos alimentos - não interferem na implementação destas compras. Cabe destacar que a estrutura pode fornecer os meios potenciais para favorecer ou prejudicar o alcance dos objetivos do Programa nas outras dimensões ${ }^{[12]}$. Contudo, a estrutura não é condição necessária para ocorrerem os processos, ela cumpre suas finalidades se os processos forem adequados ${ }^{[14]}$. Dessa forma, Tanaka et al, baseado na tríade donabidiana estrutura, processo e resultado, propõe que a avaliação tenha inicialmente o processo como foco, por se constituir no componente essencial em que a interação com o usuário concretiza a ação de saúde[22].
As ações de apoio institucional aos agricultores familiares estão associadas com a implementação das compras de alimentos da agricultura familiar. No estudo sobre os antecedentes e elementos da vinculação do PNAE com a agricultura familiar fica evidente que a implementação das compras diretas para alimentação escolar é um processo complexo e deve envolver articulação e diálogo entre distintos órgãos, setores e atores em todos os níveis de governo e sociedade civil[23]. Todavia, ainda existem desafios a serem superados para uma articulação efetiva, como em relação à identificação e registro dos agricultores, mapeamento dos alimentos produzidos, sazonalidade, logística de abastecimento, cálculo do preço de compra, assistência técnica, adequação sanitária, planejamento de cardápios escolares que reflitam a produção local[24-26].

Apenas a obrigatoriedade em lei para aquisição de alimentos agricultura familiar não é suficiente para promover cardápios de melhor qualidade nutricional. Os achados de um estudo que estimam o efeito dos programas combinados de alimentação escolar e desenvolvimento rural também verifica que apenas a aquisição de alimentos da agricultura não promove cardápios mais adequados ${ }^{[27]}$. Muito embora a legislação do programa defina claramente sobre os recursos financeiros para à aquisição direta de alimentos do agricultor familiar, a normatização apresenta fragilidades ao estabelecer uma definição geral de alimento básico e especificar apenas alguns alimentos aos restritos, sendo permissiva quanto o uso de alimentos ultraprocessados. Segundo Teo e Monteiro[28] o atendimento a legislação torna se mais exequível pela aquisição de alimentos mais extensamente processados. Esse fato evidencia a necessidade de maior detalhamento da legislação com relação ao tipo de alimentos que deverão ser adquiridos para o PNAE.

A expressiva oferta de alimentos ultraprocessados nos cardápios analisados, especialmente nos lanches, em ambos os grupos de municípios, estimulam hábitos e preferências alimentares inadequadas entre os estudantes, fato que vem em contramão dos objetivos do Programa de Alimentação Escolar estabelecidas na legislação. As políticas públicas no ambiente escolar devem 
estar relacionadas com a criação de um ambiente que favoreça as escolhas alimentares saudáveis, contribuindo para promoção e proteção da saúde, com estímulo para a preferência por alimentos in natura e minimamente processados ${ }^{[2]}$. Um modelo que contribui para este propósito é a elaboração de cardápios escolares com alimentos saudáveis, de baixo ou nenhum nível de processamento, e integrantes dos repertórios alimentares locais, quanto ao tipo de alimento $\mathrm{e}$ às formas de preparação, articuladas com os modos de comer em família e com a utilização de ingredientes do cotidiano das comunidades ${ }^{[30]}$.

A história da trajetória do PNAE é marcada por uma política assistencialista com a utilização prioritária de alimentos formulados, como sopas e mingaus, produzidos pela indústria de alimentos ${ }^{[31-32]}$. A substituição deste modelo que incentivou o consumo e a produção de alimentos ultraprocessados por outro que incentiva a produção e o consumo de alimentos locais representa um avanço para o Programa e para o fortalecimento da agricultura familiar, mas ainda existem desafios a serem superados ${ }^{21]}$. Alerta-se para a necessidade de regulamentação quanto à oferta de ultraprocessados nos cardápios das escolas [33]. Não há justificativa para o planejamento de cardápios para alimentação escolar de milhões de estudantes brasileiros contendo alimentos ultraprocessados de reconhecida inferior qualidade nutricional [34-36].

A matriz avaliativa desenvolvida neste estudo foi utilizada de forma inovadora para avaliar o efeito da legislação na qualidade nutricional da alimentação escolar do estado de São Paulo, sendo considerada uma importante estratégia para entender como esta política pública pode trazer ganhos na qualidade da alimentação dos milhões de estudantes da rede pública de educação. $\mathrm{Na}$ busca de contribuir para o avanço do conhecimento da avaliação de programas no contexto da alimentação escolar, sugere-se estudos de evidência de validade desta ferramenta proposta.
O estudo pode ter apresentado limitações na análise dos alimentos quanto ao grau de processamento, pois alguns municípios não disponibilizaram as fichas técnicas das preparações. Para minimizar esse viés foi adotado como critério para designar os alimentos presentes nos cardápios o uso de receituário padrão e na impossibilidade houve definição arbitrária do possível ingrediente principal de preparações sem receita.

\section{CONCLUSÃO}

Ambos os grupos de municípios estudados atentem obrigatoriedade da legislação quanto a oferta mínima de frutas ou hortaliças e máxima de doces. No entanto, as cidades que adquirem alimentos dos agricultores familiares apresentam porcentual de adequação elevado para o indicador "participação de alimentos básicos" e reduzido para o indicador "participação de alimentos restritos", inferindo qualidade nutricional superior. Contudo, a participação média de alimentos ultraprocessados é elevada tanto nas cidades que adquirem alimentos direto dos agricultores, quanto nos municípios que não implementaram as compras.

As fragilidades da legislação para a aquisição de alimentos da agricultura familiar devem ser exploradas para promover cardápios escolares de melhor qualidade nutricional. O marco legal apresenta lacunas quanto a definição dos alimentos que devem compor os cardápios escolares, sendo permissivo quanto ao uso de alimentos de maior nível de processamento.

Novos estudos de avaliação e monitoramento devem ser realizados em nível nacional, nos diferentes contextos das regiões brasileiras, para verificar o efeito da legislação na qualidade nutricional dos cardápios. Dessa forma, contribuindo para fomentar a agricultura local e melhorar a qualidade da alimentação escolar nos municípios. 


\section{REFERÊNCIAS}

[1] Siqueira RL, Cotta RMM, Ribeiro RCL, Sperandio N, Priore SE. Análise da incorporação da perspectiva do Direito Humano à Alimentação Adequada no desenho institucional do Programa Nacional de Alimentação Escolar. Ciência \& Saúde Coletiva [internet]. 2014 [acesso em 2017 fev 07];19(1):301-310. https://doi.org/10.1590/1413-81232014191.2114.

[2] Libermann AP, Bertolini GRF. Tendências de pesquisa em políticas públicas: uma avaliação do Programa Nacional de Alimentação Escolar - PNAE. Ciência \& Saúde Coletiva [internet]. 2015 [acesso em 2017 jan 15];20(11):3533-3546. https://doi.org/10.1590/1413-812320152011.16822014.

[3] Peixinho AML. A trajetória do Programa Nacional de Alimentação Escolar no período de 2003-2010: relato do gestor nacional. Ciênc. Saúde Coletiva [internet]. 2013 [acesso em 2017 fev 06]; 18(4)909-916. http://dx.doi.org/10.1590/S141381232013000400002 .

[4] Brasil. Presidência da República. Lei no 11.947, de 16 de junho de 2009. Dispõe sobre o atendimento da alimentação escolar e do Programa Dinheiro Direto na Escola aos alunos da educação básica; altera as Leis nos 10.880, de 9 de junho de 2004, 11.273, de 6 de fevereiro de 2006, 11.507, de 20 de julho de 2007; revoga dispositivos da Medida Provisória no 2.178-36, de 24 de agosto de 2001, e a Lei no 8.913, de 12 de julho de 1994; e dá outras providências. Brasília: Diário Oficial da União. 16 jun 2009.

[5] NDE - Fundo Nacional de Desenvolvimento da Educação. Resolução/CD/ FNDE no 26, de 17 de junho de 2013. Dispõe sobre o atendimento da alimentação escolar aos alunos da educação básica no âmbito do Programa Nacional de Alimentação Escolar PNAE. FNDE; 2013.

[6] Organización de las Naciones Unidas para la Alimentación y la Agricultura. Agricultura familiar en América Latina y el Caribe: recomendaciones de política. Santiago: Organización de las Naciones Unidas para la Alimentación y la Agricultura; 2014.

[7] Brasil. Presidência da República. Decreto no 7.272, de 25 de agosto de 2010. Regulamenta a Lei no 11.346, de 15 de setembro de 2006, que cria o Sistema Nacional de Segurança Alimentar e Nutricional - SISAN com vistas à assegurar o direito humano à alimentação adequada, institui a Política Nacional de Segurança Alimentar e Nutricional - PNSAN, estabelece os parâmetros para a elaboração do Plano Nacional de Segurança Alimentar e Nutricional, e dá outras providências. Brasília: Diário Oficial da União. 25 ago 2010.

[8] Souza AA de, Silva APF da, Azevedo E de, Ramos MO. Cardápios e sustentabilidade: ensaio sobre as diretrizes do Programa Nacional de Alimentação Escolar. Rev. Nutr. [internet]. 2015 [acesso em 2016 ago 17]; 28(2):217-229. https://doi.org/10.1590/1415-52732015000200010.

[9] Chaves LG, Mendes PNR, Brito RR, Botelho RBA. O programa nacional de alimentação escolar como promotor de hábitos alimentares regionais. Rev Nutr. [internet]. 2009 [acesso em 2016 nov 20]; 22(6):857-66. https://doi.org/10.1590/S141552732009000600007 .

[10] Hawkes C, Brazil BG, Castro IRR de, Jaime P C. How to engage across sectors: lessons from agriculture and nutrition in the Brazilian School Feeding Program. Rev. Saúde Pública [internet]. 2016; [acesso em 2017 jan 20]; 50(47). https://doi.org/10.1590/S1518-8787.2016050006506.

[11] Donabedian A. The seven pillars of quality. Arch Pathol Lab Med. 1990;114:1115-1118.

[12] Santos SMC, Santos LMP. Avaliação de políticas públicas de segurança alimentar e combate à fome. 1 - Abordagem metodológica. Cad Saúde Pública [internet]. 2007; [acesso em 2016 mar 23]; 23:1029-40. https://doi.org/10.1590/S0102311X2007000500005.

[13] Brasil. Guia alimentar para a população brasileira. Ministério da Saúde. Brasília: Ministério da Saúde; 2014.

[14] Tanaka OY, Melo C. Avaliação de Programas de Saúde: um modo de fazer. São Paulo: Editora da Universidade de São Paulo; 2001.

[15] Monteiro CA, Cannon G, Levy RB, Moubarac JC, Jaime PC, Martins AP, et al. NOVA. A estrela brilha. Classificação dos alimentos. Saúde Pública. World Nutrition. Janeiro-Março. 2016; 7(1-3):28-40.

[16] Fisberg RM, Villar BS. Manual de Receitas e Medidas Caseiras para Cálculo de Inquéritos Alimentares. São Paulo: Signus; 2002.

[17] IDHM - Índice de Desenvolvimento Humano Municipal. Atlas do Desenvolvimento Humano no Brasil [internet] 2013 [acesso em 2018 ago 22]. Disponivel em: http://www.atlasbrasil.org.br/2013/pt/o_atlas/idhm.

[18] IBGE - Instituto Brasileiro de Geografia e Estatística [internet]. 2018 [acesso em 2018 jul 20]. Disponível em: http://www.cidades.ibge.gov.br/xtras/home.php.

[19] Costa BAL, Amorim Junior PCG, Silva MG. As cooperativas de agricultura familiar e o mercado de compras governamentais em Minas Gerais. Revista de Economia Sociologia Rural [internet]. 2015 [acesso em 2017 fev 10]; 53:109-126. http://dx.doi.org/10.1590/1234-56781806-9479005301006.

[20] Villar BS, Schwartzman F, Januario BL, Ramos JF. Situação dos municípios do estado de São Paulo com relação à compra direta de produtos da agricultura familiar. Rev Bras Epidemiol [internet]. 2013 [acesso em 2016 jun 10]; 16(1):223-226. http://dx.doi.org/10.1590/S1415-790X2013000100021.

[21] Soares P, Martinelli SS, Melgarejo L, Davó-Blanes MC, Cavalli SB. Potencialidades e dificuldades para o abastecimento da 
alimentação escolar mediante a aquisição de alimentos da agricultura familiar em um município brasileiro. Ciênc. Saúde Coletiva [internet]. 2015 [acesso em 2018 mai 11]; 20(6):1891-1900. http://dx.doi.org/10.1590/1413-81232015206.16972014.

[22] Schwartzman F, Mora CAR, Bogus CM, Villar BS. Antecedentes e elementos da vinculação do programa de alimentação escolar do Brasil com a agricultura familiar. Cad. Saúde Pública [internet]. 2017 [acesso em 2018 abr 25]; 33(12):e00099816.http://dx.doi.org/http://dx.doi.org/10.1590/01 02-311x00099816.

[23] Saraiva EB, Silva APF, Sousa AA, Cerqueira GF, Chagas CMS, Toral N. Panorama da compra de alimentos da agricultura familiar para o Programa Nacional de Alimentação Escolar. Cien Saúde Coletiva [internet]. 2013 [acesso em 2016 out 08]; 18,927-936. http://dx.doi.org/10.1590/S1413-81232013000400004.

[24] Tanaka OY, Ribeiro EL, Almeida CL de. Avaliação em Saúde: contribuições para a incorporação no cotidiano. São Paulo: Atheneu Editora; 2017.

[25] Triches RM, Schneider S. Alimentação escolar e agricultura familiar: reconectando o consumo à produção. Saúde Soc [internet]. 2010 [acesso em 2017 jan 10];19(4):933945.http://dx.doi.org/http://dx.doi.org/10.1590/S010412902010000400019.

[26] Souza-Esquerdo VF de, Bergamasco SMPP. Análise sobre o acesso aos programas de políticas públicas da agricultura familiar nos municípios do circuito das frutas (SP). Revista de Economia e Sociologia Rural [internet]. 2014 [acesso em 2018 jun 15];52(1),205222. https://dx.doi.org/10.1590/S0103-20032014000600011.

[27] Belik W, Domene SMA. Experiências de programas combinados de alimentação escolar e desenvolvimento local em São Paulo. Agroalimentaria [internet]. 2012 [acesso em $2016 \mathrm{dez}$ 05];18,57-72. http://dx.doi.org/10.1590/1413812320152011.16822014

[28] Teo CRPA, Monteiro CA. Marco legal do Programa Nacional de Alimentação Escolar: uma releitura para alinhar propósitos e práticas na aquisição de alimentos. Rev. Nutr. [internet]. 2012 [acesso em 2016 dez 05];25(5):657-668.
http://dx.doi.org/10.1590/S1415-52732012000500010.

[29] Hawkes C, Smith TG, Jewel J et al. Smart food policies for obesity prevention. Lancet [internet]. 2015; [acesso em 2016 out 20];385,2410-2421. http://dx.doi.org/10.1016/S01406736(14)61745-1.

[30] Gabriel CG, Costa L da CF, Calvo MCM, Vasconcelos F de AG de. Planejamento de cardápios para escolas públicas municipais: reflexão e ilustração desse processo em duas capitais brasileiras. Rev. Nutr. 2012;25(3):363-372.

[31] Coimbra M, Meira JFP, Starling MBL. Comer e aprender: uma história da alimentação escolar no Brasil. Belo Horizonte: MEC/INAE; 1982.

[32] L'Abbate S. As Políticas de Alimentação e Nutrição no Brasil: I. Período de 1940 a 1964. Rev Nutr. 1988;1(2)87-138.

[33] Monteiro CA, Levy RB, Claro RM, et al. Increasing consumption of ultra-processed foods and likely impact on human health: evidence from Brazil. Public Health Nutr [internet]. 2011 [acesso em 2016 dez 05]; 14(1):5-13. https://doi.org/10.1017/S1368980010003241.

[34] Bielemann, RM Motta, JVS Minten GC, et al. Consumo de alimentos ultraprocessados e impacto na dieta de adultos jovens. Rev Saúde Pública [internet]. 2015 [acesso em 2018 ago 09]; 49(28):1-10. http://dx.doi.org/10.1590/S00348910.2015049005572.

[35] Barcelos GT, Rauber F, Vitolo, MR. Produtos processados e ultraprocessados e ingestão de nutrientes em crianças. Revista Ciência \& Saúde. 2014;7(3):155-161.

[36] Costa C dos S, Flores TR, Wendt A, et al. Comportamento sedentário e consumo de alimentos ultraprocessados entre adolescentes brasileiros: Pesquisa Nacional de Saúde do Escolar (PeNSE), 2015. Cad. Saúde Pública [internet]. 2018 [acesso em 2019 jan 04];34(3). https://doi.org/10.1590/0102-311X00021017. 
Apêndice 1. Distribuição dos municípios do estado de São Paulo que adquirem e não adquirem gêneros da agricultura familiar, de acordo com grupos de alimentos nos cardápios. São Paulo, Brasil, 2013

\begin{tabular}{|c|c|c|c|}
\hline \multicolumn{2}{|c|}{ Variáveis } & $\begin{array}{c}\text { Compra da Agricultura } \\
\text { Familiar } \\
\%(n) \\
\end{array}$ & $\begin{array}{c}\text { Não Compra da Agricultura } \\
\text { Familiar } \\
\%(\mathrm{n}) \\
\end{array}$ \\
\hline \multicolumn{4}{|c|}{ In natura e minimamente processados } \\
\hline \multirow{4}{*}{ Hortaliças } & Nenhuma vez & $5,6(1)$ & $0,0(0)$ \\
\hline & 1 ou 2 vezes & $11,1(3)$ & $14,9(1)$ \\
\hline & 3 ou 4 vezes & $22,2(4)$ & $28,5(2)$ \\
\hline & 5 ou mais vezes & $61,1(11)$ & $57,2(4)$ \\
\hline \multirow[t]{3}{*}{ Frutas } & Nenhuma vez & $27,8(5)$ & $28,6(2)$ \\
\hline & 1 ou 2 vezes & $55,6(10)$ & $57,2(4)$ \\
\hline & 3 ou 4 vezes & $16,7(3)$ & $14,3(1)$ \\
\hline \multirow[t]{3}{*}{ Raízes e Tubérculos } & Nenhuma vez & $16,7(3)$ & $42,9(3)$ \\
\hline & 1 ou 2 vezes & $72,2(13)$ & $57,2(4)$ \\
\hline & 3 ou 4 vezes & $11,1(2)$ & $0,0(0)$ \\
\hline \multirow[t]{3}{*}{ Cereais e Macarrão } & 1 ou 2 vezes & $5,6(1)$ & $0,0(0)$ \\
\hline & 3 ou 4 vezes & $33,3(6)$ & $42,9(3)$ \\
\hline & 5 ou mais vezes & $61,1(11)$ & $57,2(4)$ \\
\hline \multirow[t]{4}{*}{ Feijões } & Nenhuma vez & $5,6(1)$ & $0,0(0)$ \\
\hline & 1 ou 2 vezes & $38,9(7)$ & $42,9(3)$ \\
\hline & 3 ou 4 vezes & $50,0(9)$ & $28,6(2)$ \\
\hline & 5 ou mais vezes & $5,6(1)$ & $28,57(2)$ \\
\hline \multirow[t]{3}{*}{ Carnes e Ovos } & 1 ou 2 vezes & $16,7(3)$ & $0,0(0)$ \\
\hline & 3 ou 4 vezes & $50,0(9)$ & $57,1(4)$ \\
\hline & 5 ou mais vezes & $33,3(6)$ & $42,9(3)$ \\
\hline \multirow[t]{3}{*}{ Leite de vaca } & Nenhuma vez & $61,1(11)$ & $28,6(2)$ \\
\hline & 3 ou 4 vezes & $5,6(1)$ & $0,0(0)$ \\
\hline & 5 ou mais vezes & $33,3(6)$ & $71,4(5)$ \\
\hline \multicolumn{4}{|l|}{ Ingredientes culinários } \\
\hline \multirow{2}{*}{ Sal } & Até 4 vezes & $50,0(9)$ & $28,6(2)$ \\
\hline & 5 ou mais vezes & $50,0(9)$ & $71,4(5)$ \\
\hline \multirow[t]{2}{*}{ Óleo } & Até 4 vezes & $38,9(7)$ & $28,6(2)$ \\
\hline & 5 ou mais vezes & $61,1(11)$ & $71,4(5)$ \\
\hline \multirow{4}{*}{ Vinagre } & Nenhuma vez & $5,6(1)$ & $14,3(1)$ \\
\hline & 1 ou 2 vezes & $44,4(8)$ & $14,3(1)$ \\
\hline & 3 ou 4 vezes & $11,1(7)$ & $54,1(4)$ \\
\hline & 5 ou mais vezes & $11,1(2)$ & $14,3(1)$ \\
\hline \multicolumn{4}{|l|}{ Processados } \\
\hline \multirow[t]{2}{*}{ Molho de tomate } & Nenhuma vez & $44,4(8)$ & $28,6(2)$ \\
\hline & 1 ou 2 vezes & $55,6(10)$ & $71,4(5)$ \\
\hline \multirow[t]{2}{*}{ Milho ou ervilha } & Nenhuma vez & $77,8(14)$ & $71,4(5)$ \\
\hline & 1 ou 2 vezes & $22,2(4)$ & $28,6(2)$ \\
\hline \multirow[t]{2}{*}{ Queijo } & Nenhuma vez & $88,9(16)$ & $100,0(7)$ \\
\hline & 1 ou 2 vezes & $11,1(2)$ & $0,0(0)$ \\
\hline \multirow[t]{2}{*}{ Sardinha } & Nenhuma vez & $94,4(17)$ & $85,7(6)$ \\
\hline & 1 ou 2 vezes & $5,6(1)$ & $14,3(1)$ \\
\hline \multirow[t]{2}{*}{ Geléia } & Nenhuma vez & $88,9(16)$ & $100,0(7)$ \\
\hline & 1 ou 2 vezes & $11,1(2)$ & $0,0(0)$ \\
\hline \multicolumn{4}{|l|}{ Ultraprocessados } \\
\hline Pão industrializado & Nenhuma vez & $22,2(4)$ & $0,0(0)$ \\
\hline & 1 ou 2 vezes & $27,8(5)$ & $28,6(2)$ \\
\hline & 3 ou 4 vezes & $27,8(5)$ & $28,6(2)$ \\
\hline & 5 ou mais vezes & $22,2(4)$ & $42,9(3)$ \\
\hline Biscoito industrializado & Nenhuma vez & $50,0(9)$ & $57,1(4)$ \\
\hline & 1 ou 2 vezes & $33,3(6)$ & $28,6(2)$ \\
\hline & 3 ou 4 vezes & $11,1(2)$ & $14,3(1)$ \\
\hline & 5 ou mais vezes & $5,6(1)$ & $0,0(0)$ \\
\hline
\end{tabular}


Apêndice 1. Continuação. Distribuição dos municípios do estado de São Paulo que adquirem e não adquirem gêneros da agricultura familiar, de acordo com grupos de alimentos nos cardápios. São Paulo, Brasil, 2013

\begin{tabular}{|c|c|c|c|}
\hline & & $\begin{array}{c}\text { Compra da Agricultura } \\
\text { Familiar } \\
\%(\mathrm{n}) \\
\end{array}$ & $\begin{array}{c}\text { Não Compra da Agricultura } \\
\text { Familiar } \\
\%(\mathrm{n})\end{array}$ \\
\hline \multirow[t]{2}{*}{ Bolo industrializado } & Nenhuma vez & $83,3(15)$ & $85,7(6)$ \\
\hline & 1 ou 2 vezes & $16,7(3)$ & $14,3(1)$ \\
\hline \multirow[t]{3}{*}{ Embutidos } & Nenhuma vez & $33,3(6)$ & $57,1(4)$ \\
\hline & 1 ou 2 vezes & 61,1 (11) & $42,9(3)$ \\
\hline & 3 ou 4 vezes & $5,6(1)$ & $0,0(0)$ \\
\hline \multirow[t]{2}{*}{ Nuggets ou Almondegas } & Nenhuma vez & $88,9(16)$ & $100,0(7)$ \\
\hline & 1 ou 2 vezes & $11,1(2)$ & $0,0(0)$ \\
\hline \multirow[t]{4}{*}{ Achocolatado } & Nenhuma vez & $77,8(14)$ & $42,9(3)$ \\
\hline & 1 ou 2 vezes & $0,0(0)$ & $14,3(1)$ \\
\hline & 3 ou 4 vezes & $5,6(1)$ & $0,0(0)$ \\
\hline & 5 ou mais vezes & $16,7(3)$ & $42,9(3)$ \\
\hline \multirow[t]{4}{*}{ Néctar de fruta } & Nenhuma vez & $50,0(9)$ & $57,1(4)$ \\
\hline & 1 ou 2 vezes & $38,9(7)$ & $42,9(3)$ \\
\hline & 3 ou 4 vezes & $5,6(1)$ & $0,0(0)$ \\
\hline & 5 ou mais vezes & $5,6(1)$ & $0,0(0)$ \\
\hline \multirow[t]{3}{*}{ Gelatina } & Nenhuma vez & $88,9(16)$ & $85,7(6)$ \\
\hline & 1 ou 2 vezes & $5,6(1)$ & $14,3(1)$ \\
\hline & 3 ou 4 vezes & $5,6(1)$ & $0,0(0)$ \\
\hline \multirow[t]{3}{*}{ Iogurte e Bebida Láctea } & Nenhuma vez & $77,8(14)$ & $71,4(5)$ \\
\hline & 1 ou 2 vezes & $11,1(2)$ & $14,3(1)$ \\
\hline & 5 ou mais vezes & $11,1(2)$ & $14,3(1)$ \\
\hline \multirow[t]{4}{*}{ Margarina } & Nenhuma vez & $50,0(9)$ & $14,3(1)$ \\
\hline & 1 ou 2 vezes & $33,3(6)$ & $28,6(2)$ \\
\hline & 3 ou 4 vezes & $5,6(1)$ & $28,6(2)$ \\
\hline & 5 ou mais vezes & $11,1(2)$ & $28,6(2)$ \\
\hline \multirow[t]{2}{*}{ Batata palha } & Nenhuma & $94,4(17)$ & $100,0(7)$ \\
\hline & 1 ou 2 vezes & $4,0(1)$ & $0,0(0)$ \\
\hline
\end{tabular}

